\title{
FORMAÇÃO E MATURAÇÃO DA UVA E OS EFEITOS SOBRE OS VINHOS: REVISÃO
}

FORMATION AND RIPENING OF GRAPE AND EFFECTS ON THE WINES: REVIEW

\begin{abstract}
Marcelo Borghezan*
Departamento de Fitotecnia, CCA/Universidade Federal de Santa Catarina, Rodovia Admar Gonzaga, 1346, CEP 88.034-001 Itacurubi, Florianópolis, Santa Catarina, Brasil.
\end{abstract}

*corresponding author: Tel: + 55 (48) 3721-5443, email: mborghezan@hotmail.com

(Manuscrito recebido em 12.06.2017. Aceite para publicação em 22.09.2017)

\section{RESUMO}

O processo de ontogênese das bagas envolve muitas mudanças durante o desenvolvimento, embora o período de maior importância seja a fase de maturação. O objetivo desta revisão foi descrever os processos envolvidos na formação e maturação da uva, com uma abordagem direcionada para as variedades viníferas, e os efeitos sobre a composição e a qualidade dos vinhos. Serão atualizados conceitos básicos para a compreensão da estrutura anatômica, dos processos fisiológicos e bioquímicos envolvidos no desenvolvimento da uva, além do efeito do manejo e das condições meteorológicas sobre a maturação das bagas. Será discutido como a formação das bagas está ligada aos demais processos de desenvolvimento da videira. Uma grande complexidade de eventos regula e modifica a concentração e a diversidade de compostos químicos nas diferentes partes da baga. Os temas abordados têm a finalidade de permitir o melhor aproveitamento das condições do meio onde os vinhedos estão implantados, bem como a adoção ou o ajuste de práticas de manejo que possibilitem a produção de uvas com maior qualidade.

\section{SUMMARY}

Berries ontogenesis process involves many changes during development, although the most important period is the ripening phase. The objective of this review was to describe the processes involved in the formation and ripening of the grape, with a directed approach to the wine grape varieties, and the effects on the composition and quality of wines. Basic concepts will be updated to understand the anatomical structure, the physiological and biochemical processes involved in grape development, and the effect of management and meteorological conditions on the ripening of berries. It will be discussed how the formation of the berries is linked to the other processes of grapevine development. A great complexity of events regulates and modifies the concentration and the diversity of chemical compounds in the different parts of the berry. The subjects discussed have the purpose of allowing the best use of the vineyard environment conditions, as well as the adoption or adjustment of management practices that allow the production of grapes with higher quality.

Palavras-chave: Vitis vinifera L., ontogênese, composição das bagas, pintor, índices de colheita. Key words: Vitis vinifera L., ontogenesis, berries composition, veraison, harvest index.

\section{INTRODUÇÃO}

A uva é um fruto simples, formado a partir do desenvolvimento do ovário após a fecundação (Fregoni, 1999; Conde et al., 2007; Keller, 2010; Kuhn et al., 2013). Os conhecimentos a respeito dos processos fisiológicos e bioquímicos envolvidos na formação e maturação da uva tem sido intensamente ampliados e revisados (Coombe e McCarthy, 2000; Robinson e Davies, 2000; Ollat et al., 2002; Adams, 2006; Conde et al., 2007). Avanços na compreensão do desenvolvimento, na fisiologia e na composição das bagas apresentam uma visão mais ampla da ligação entre o metabolismo da videira e as condições do meio, além da relação entre as características da uva e as propriedades químicas e sensoriais dos vinhos (Chatelet et al., 2008; Kuhn et al., 2013; Teixeira et al., 2013; Fortes et al., 2015; GonzálesBarreiro et al., 2015; Ilc et al., 2016).

O objetivo desta revisão foi sintetizar parte dos progressos envolvidos na compreensão dos processos de formação e maturação da uva, com uma

This is an Open Access article distributed under the terms of the Creative Commons Attribution License (http://creativecommons.org/licenses/by/4.0), which permits unrestricted use, distribution, and reproduction in any medium, provided the original work is properly cited. 
abordagem direcionada para as variedades viníferas destinadas à elaboração de vinhos.

\section{ESTRUTURA DA BAGA}

O cacho da videira é formado por um conjunto variável de bagas, que estão conectadas diretamente à planta através dos feixes vasculares (floema e xilema) que passam no interior do pedicelo e do pedúnculo. Nas bagas maduras, a polpa e a película são os principais constituintes. Dependendo da variedade, a película representa de 8 a $20 \%$ do peso, enquanto as sementes chegam a menos de $6 \%$ do peso final da baga. A ráquis ou engaço alcança de 3 a $7 \%$ do peso final do cacho (Ribéreau-Gayon et al., 2006). Na polpa, a água é o componente mais abundante, variando entre $75-85 \%$ do volume, no momento da colheita (Conde et al., 2007; Keller, 2010). Outros constituintes são açúcares, ácidos orgânicos, compostos nitrogenados (aminoácidos livres e proteínas), compostos fenólicos (flavonóides e não flavonóides), sais inorgânicos, compostos aromáticos, além de outros voláteis e hormônios (Fregoni, 1999; Conde et al., 2007; Keller, 2010; Bondada e Keller, 2012; Kuhn et al., 2013).

O fruto é formado pelo exocarpo (película ou casca), que possui de 11 a 12 camadas de células, pelo mesocarpo (polpa) que contém entre 25 e 30 camadas celulares e pelo endocarpo, formado por uma fina camada envolvendo as sementes (Ollat et al., 2002; Kuhn et al., 2013). No ápice da baga, oposto ao pedicelo, observa-se a presença dos vestígios florais (estilete e estigma) (Figura 1a e 1b). O transporte de água e compostos no interior da baga ocorre através dos feixes vasculares (vasos de xilema e floema) centrais e periféricos (Figura 1c e 1d) (Ollat et al., 2002; Conde et al., 2007; Chatelet et al., 2008).

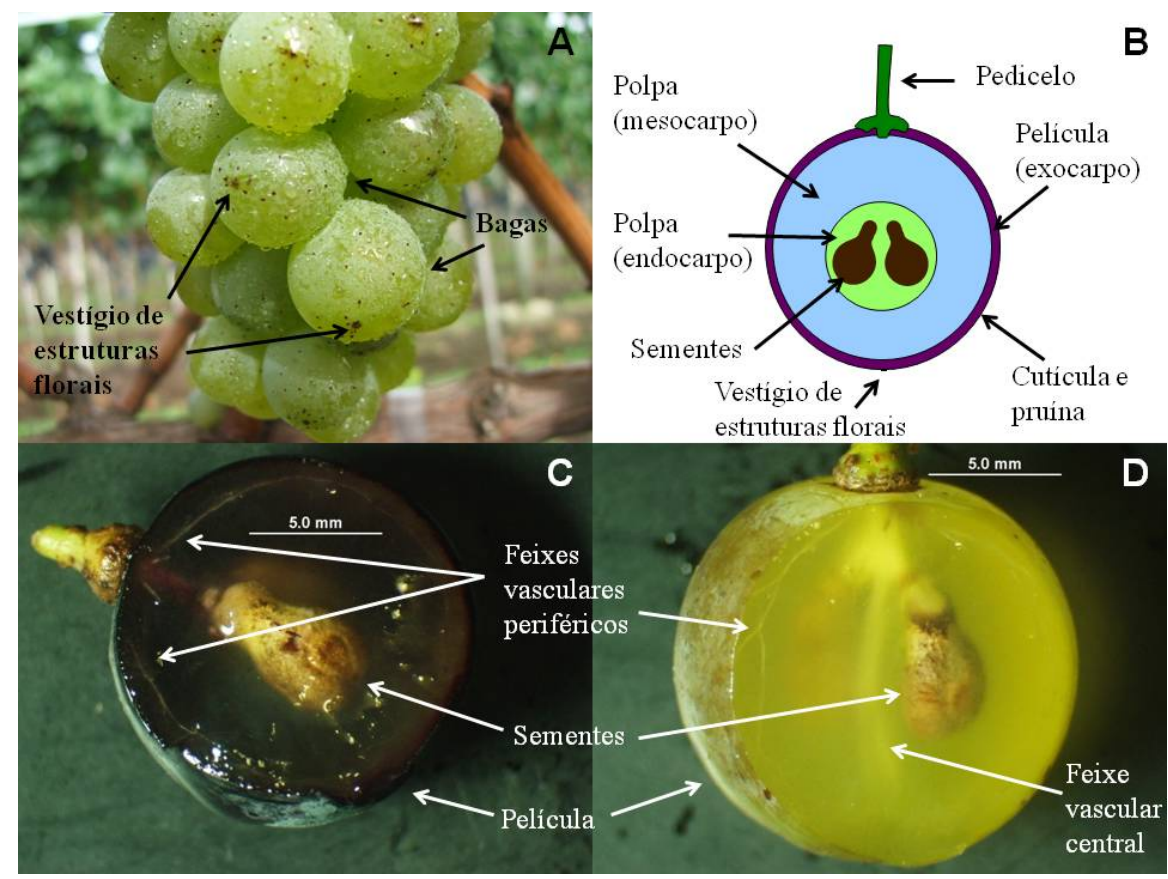

Figura 1. Seção do cacho da 'Sauvignon Blanc’ (A), representação esquemática da estrutura anatômica da baga (B), seção longitudinal de baga de 'Cabernet Sauvignon' (C) e 'Sauvignon Blanc' (D) durante a maturação.

Section of the bunch of the 'Sauvignon Blanc' (A), schematic representation of the anatomical structure of the berry (B), longitudinal section of 'Cabernet Sauvignon' (C) and 'Sauvignon Blanc' (D) during berry ripening.

As células da epiderme secretam externamente uma cutícula lipídica, recobrindo toda a superfície da baga. Acima da cutícula, observa-se uma camada epicuticular, espessa e visível, denominada pruína (Figura 1c e 1d) (Conde et al., 2007; Keller, 2010; Bondada e Keller, 2012). Essas camadas cerosas são acumuladas desde o início da formação da baga, apresentando função protetora (transpiração, radiação, injúrias físicas e como barreira aos patógenos), importância enológica (manutenção de leveduras e bactérias) e efeito estético (atratividade visual) 
(Bondada e Keller, 2012), além de propriedades bioativas.

Diversos microorganismos, incluindo fungos filamentosos (parasitas e saprófitos), leveduras e bactérias, colonizam de forma irregular a superfície das bagas (Barata et al., 2012; Gilbert et al., 2014). Próximo à colheita, o número de leveduras nativas pode variar entre $10^{3}$ e $10^{6}$ unidades formadoras de colônias/g (Ribéreau-Gayon et al., 2006), sendo que a Sacharomices cerevisae, quando presente, apresentase em baixa frequência (Barata et al., 2012). Climas mais quentes possibilitam a coexistência de populações maiores de microorganismos. Distintas espécies de leveduras e bactérias são encontradas na uva, promovendo tanto atividades fermentativas, quanto a degradação do vinho. A diversidade da microflora depende do local de cultivo, do manejo adotado no vinhedo e do estágio de maturação (Barata et al., 2012; Gilbert et al., 2014). Esses autores afirmam que os microorganismos nativos, associados às uvas, desempenham efeito importante nas características químicas e sensoriais dos vinhos, embora essa ação ainda necessite ser desvendada. Também foi demonstrado que existe uma associação não aleatória entre as populações de microorganismos na superfície das bagas e a variedade, a safra e as condições climáticas (Bokulich et al., 2013). Estes autores sugeriram que o padrão de diversidade de microorganismos é relacionado com as condições específicas do vinhedo, implicando a existência do que chamaram de "terroir microbiano", que determina um fator regional de variação sobre a uva e os vinhos.

\section{FORMAÇÃO DAS BAGAS}

O crescimento do bago da uva apresenta padrão duplo sigmoide (Figuras 2, 3 e 4), resultando em dois estágios consecutivos de crescimento, separados por uma fase limitada de ganho de massa (Winkler et al., 1974; Coombe e McCarthy, 2000; Kennedy et al., 2000; Keller, 2010; Paul et al., 2012). Com a frutificação, vingamento ou fixação dos frutos (fruit set), ocorrem inicialmente, o desenvolvimento das estruturas das sementes e o aumento significativo no número de células do exocarpo e do endocarpo.

O desenvolvimento das bagas pode ser compreendido a partir da divisão em três fases (Figura 4), conforme apresentado por Kennedy et al. (2000). Na primeira fase ocorre a diferenciação dos tecidos e estruturas da baga, e o acúmulo intenso de reservas. Neste momento, as bagas apresentam tamanho pequeno, consistência firme, elevada acidez da polpa (Robinson e Davies, 2000; Conde et al., 2007; Keller, 2010), coloração verde e preferencialmente o ácido málico como composto orgânico acumulado (Coombe e McCarthy, 2000). Esta etapa também é marcada pelo acúmulo de compostos fenólicos, de precursores de compostos voláteis e de minerais, além da formação de alguns compostos aromáticos (Conde et al., 2007; Kuhn et al., 2013; Gonzáles-Barreiro et al., 2015) e da biossíntese de compostos fenólicos nas sementes (Figura 4) (Kennedy et al., 2000; Ristic e Iland, 2005). Por ser um período de elevada atividade metabólica, a fase inicial de crescimento das bagas também é conhecida como fase lag ou fase herbácea da frutificação (Conde et al., 2007). Divisão celular acelerada é observada, estabelecendo quase a totalidade do número de células da baga (Dokoozlian, 2000; Ollat et al., 2002). A maior parte do crescimento das sementes ocorre nesta primeira fase do desenvolvimento das bagas (Ollat et al., 2002; Ristic e Iland, 2005). A atividade respiratória é elevada e vai reduzindo gradualmente, apresentando típico padrão de frutos não climatéricos (Figura 2) (Paul et al., 2012).

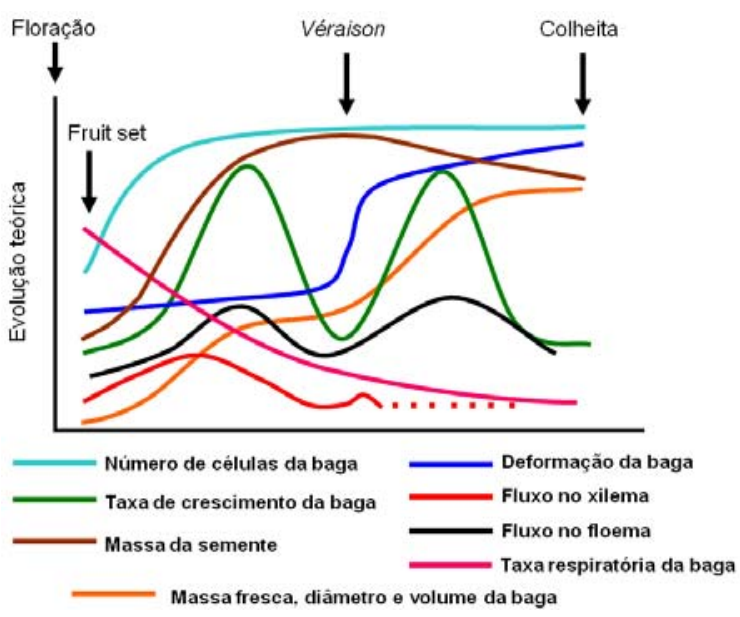

Figura 2. Alterações físicas e estruturais durante o desenvolvimento das bagas. Elaborado a partir de Fregoni (1999) (massa fresca, diâmetro e volume, taxa de crescimento), Coombe e McCarty (2000) (volume da baga, deformação, fluxo no floema e fluxo no xilema), Dokoozlian (2000) (número de células), Kennedy et al. (2000) (massa da semente), Ollat et al. (2002) (massa fresca, taxa de crescimento, taxa respiratória), Ristic e Iland (2005) (massa da semente) e Paul et al. (2012) (taxa respiratória).

Physical and structural changes during berries development. Elaborated from Fregoni (1999) (fresh mass, diameter and volume, growth rate), Coombe and McCarty (2000) (volume, deformation, flow in the phloem and flow in the xylem), Dokoozlian (2000) (number of cells), Kennedy et al. (2000) (seed mass), Ollat et al. (2002) (fresh mass, growth rate, respiration rate), Ristic e Iland (2005) (seed mass) and Paul et al. (2012) (respiration rate). 
(Bondada e Keller, 2012), além de propriedades bioativas.

Diversos microorganismos, incluindo fungos filamentosos (parasitas e saprófitos), leveduras e bactérias, colonizam de forma irregular a superfície das bagas (Barata et al., 2012; Gilbert et al., 2014). Próximo à colheita, o número de leveduras nativas pode variar entre $10^{3}$ e $10^{6}$ unidades formadoras de colônias/g (Ribéreau-Gayon et al., 2006), sendo que a Sacharomices cerevisae, quando presente, apresentase em baixa frequência (Barata et al., 2012). Climas mais quentes possibilitam a coexistência de populações maiores de microorganismos. Distintas espécies de leveduras e bactérias são encontradas na uva, promovendo tanto atividades fermentativas, quanto a degradação do vinho. A diversidade da microflora depende do local de cultivo, do manejo adotado no vinhedo e do estágio de maturação (Barata et al., 2012; Gilbert et al., 2014). Esses autores afirmam que os microorganismos nativos, associados às uvas, desempenham efeito importante nas características químicas e sensoriais dos vinhos, embora essa ação ainda necessite ser desvendada. Também foi demonstrado que existe uma associação não aleatória entre as populações de microorganismos na superfície das bagas e a variedade, a safra e as condições climáticas (Bokulich et al., 2013). Estes autores sugeriram que o padrão de diversidade de microorganismos é relacionado com as condições específicas do vinhedo, implicando a existência do que chamaram de "terroir microbiano", que determina um fator regional de variação sobre a uva e os vinhos.

\section{FORMAÇÃO DAS BAGAS}

O crescimento do bago da uva apresenta padrão duplo sigmoide (Figuras 2, 3 e 4), resultando em dois estágios consecutivos de crescimento, separados por uma fase limitada de ganho de massa (Winkler et al., 1974; Coombe e McCarthy, 2000; Kennedy et al., 2000; Keller, 2010; Paul et al., 2012). Com a frutificação, vingamento ou fixação dos frutos (fruit set), ocorrem inicialmente, o desenvolvimento das estruturas das sementes e o aumento significativo no número de células do exocarpo e do endocarpo.

O desenvolvimento das bagas pode ser compreendido a partir da divisão em três fases (Figura 4), conforme apresentado por Kennedy et al. (2000). Na primeira fase ocorre a diferenciação dos tecidos e estruturas da baga, e o acúmulo intenso de reservas. Neste momento, as bagas apresentam tamanho pequeno, consistência firme, elevada acidez da polpa (Robinson e Davies, 2000; Conde et al., 2007; Keller, 2010), coloração verde e preferencialmente o ácido málico como composto orgânico acumulado (Coombe e McCarthy, 2000). Esta etapa também é marcada pelo acúmulo de compostos fenólicos, de precursores de compostos voláteis e de minerais, além da formação de alguns compostos aromáticos (Conde et al., 2007; Kuhn et al., 2013; Gonzáles-Barreiro et al., 2015) e da biossíntese de compostos fenólicos nas sementes (Figura 4) (Kennedy et al., 2000; Ristic e Iland, 2005). Por ser um período de elevada atividade metabólica, a fase inicial de crescimento das bagas também é conhecida como fase lag ou fase herbácea da frutificação (Conde et al., 2007). Divisão celular acelerada é observada, estabelecendo quase a totalidade do número de células da baga (Dokoozlian, 2000; Ollat et al., 2002). A maior parte do crescimento das sementes ocorre nesta primeira fase do desenvolvimento das bagas (Ollat et al., 2002; Ristic e Iland, 2005). A atividade respiratória é elevada e vai reduzindo gradualmente, apresentando típico padrão de frutos não climatéricos (Figura 2) (Paul et al., 2012).

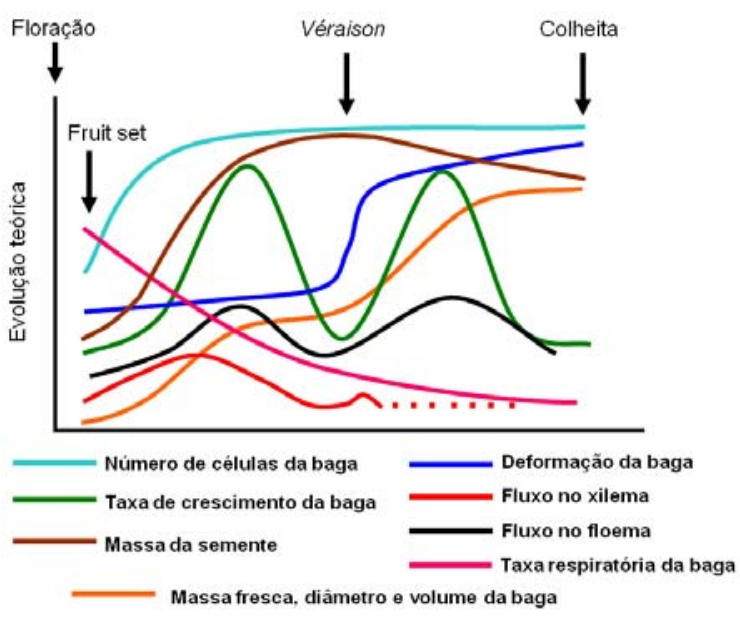

Figura 2. Alterações físicas e estruturais durante o desenvolvimento das bagas. Elaborado a partir de Fregoni (1999) (massa fresca, diâmetro e volume, taxa de crescimento), Coombe e McCarty (2000) (volume da baga, deformação, fluxo no floema e fluxo no xilema), Dokoozlian (2000) (número de células), Kennedy et al. (2000) (massa da semente), Ollat et al. (2002) (massa fresca, taxa de crescimento, taxa respiratória), Ristic e Iland (2005) (massa da semente) e Paul et al. (2012) (taxa respiratória).

Physical and structural changes during berries development. Elaborated from Fregoni (1999) (fresh mass, diameter and volume, growth rate), Coombe and McCarty (2000) (volume, deformation, flow in the phloem and flow in the xylem), Dokoozlian (2000) (number of cells), Kennedy et al. (2000) (seed mass), Ollat et al. (2002) (fresh mass, growth rate, respiration rate), Ristic e Iland (2005) (seed mass) and Paul et al. (2012) (respiration rate). 


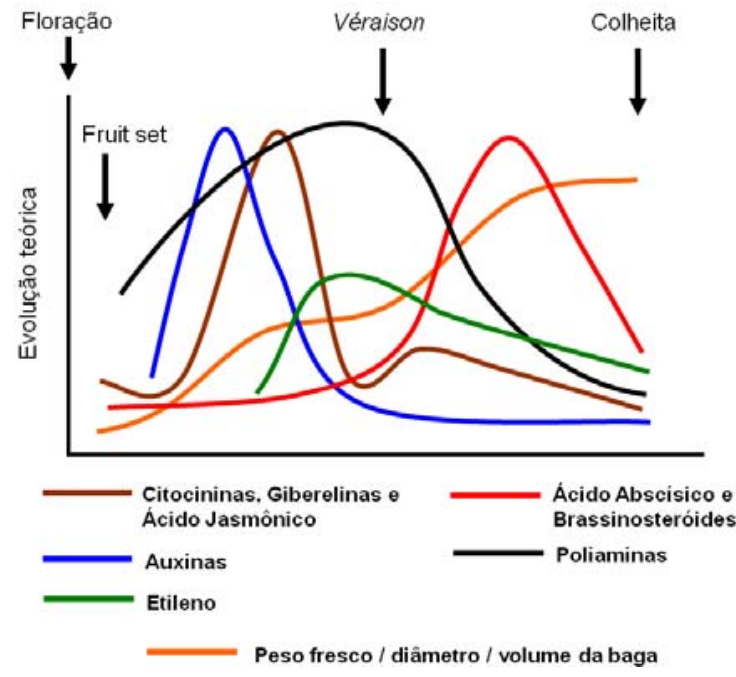

Figura 3. Alterações no crescimento e nos níveis hormonais durante o desenvolvimento das bagas. Elaborado a partir de Fregoni (1999) (massa fresca, diâmetro e volume), Coombe e McCarty (2000) (volume da baga), Conde et al. (2007) (auxinas, citocininas, giberelinas, etileno, ácido abscísico e brassinosteroides), Davies e Bottcher (2009) (auxinas, citocininas, giberelinas, etileno, ácido abscísico e brassinosteroides) e Fortes et al. (2015) (auxinas, citocininas, giberelinas, ácido jasmônico, poliaminas, etileno, ácido abscísico e brassinosteroides).

Changes in growth and hormone levels during berries development. Elaborated from Fregoni (1999) (fresh mass, diameter and volume), Coombe e McCarty (2000) (volume), Conde et al. (2007) (auxins, cytokinins, gibberellins, ethylene, abscisic acid and brassinosteroids), Davies e Bottcher (2009) (auxins, cytokinins, gibberellins, ethylene, abscisic acid and brassinosteroids), and Fortes et al. (2015) (auxins, cytokinins, gibberellins, jasmonic acid, polyamine, ethylene, abscisic acid and brassinosteroides).

O início da segunda fase de crescimento coincide com o início da maturação (ou pintor), identificada nas variedades brancas pelo amolecimento das bagas e, nas variedades tintas, também pela mudança na coloração das películas. Este estágio também é reconhecido pelo termo francês véraison (Fregoni, 1999; Coombe e McCarthy, 2000; Kennedy et al., 2000; Ribéreau-Gayon et al., 2006; Conde et al., 2007; Keller, 2010). Este estádio marca a transição no desenvolvimento das sementes, que atingem o máximo peso fresco e seco (Figura 2), passando da formação para a secagem e maturação (Ristic e Iland, 2005). Esta etapa é relativamente curta em relação à fase anterior. É caracterizada pelo desenvolvimento do embrião, endurecimento do tegumento e inicio do processo de desidratação das sementes. Os compostos fenólicos acumulados começam a ser oxidados, resultando em alteração na coloração (Kennedy et al., 2000), que ocorre simultaneamente à lignificação do tegumento (Adams, 2006).
Na segunda fase de crescimento, ocorrem modificações menos expressivas nas características estruturais, mas grandes alterações na composição química das bagas (Figura 4) (Coombe e McCarthy, 2000; Robinson e Davies, 2000; Ollat et al., 2002). Resultam em frutos com sabor doce, textura macia, aromáticos e com coloração intensa para as variedades tintas. No período entre o início da maturação e a colheita, a baga geralmente dobra de tamanho, apresentando distinções importantes com a primeira fase de crescimento (Conde et al., 2007; Keller, 2010).

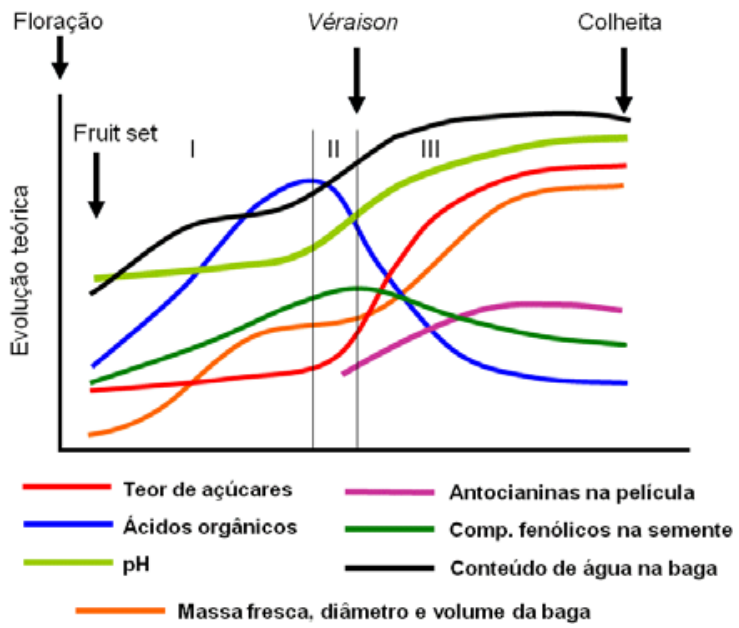

Figura 4. Alterações nos compostos químicos durante o desenvolvimento das bagas. Elaborado a partir de Fregoni (1999) (massa fresca, diâmetro e volume), Coombe e McCarty (2000) (volume da baga, açúcares), Ollat et al. (2002) (massa fresca, açúcares), Ristic e Iland (2005) (antocianinas e compostos fenólicos das sementes), Conde et al. (2007), Keller (2010) (conteúdo de água, açúcares, acidez, pH e antocianinas), Teixeira et al. (2013) (antocianinas) e Bobeica et al. (2015) (açúcares, acidez e antocianinas)

Changes in chemical compounds during berries development. Elaborated from Fregoni (1999) (fresh mass, diameter and volume), Coombe e McCarty (2000) (volume, sugars), Ollat et al. (2002) (fresh mass, sugars), Ristic e Iland (2005) (anthocyanins and total phenolics of seeds), Conde et al. (2007), Keller (2010) (water content, sugars, acidity, $\mathrm{pH}$ and anthocyanins), Teixeira et al. (2013) (anthocyanins) e Bobeica et al. (2015) (sugars, acidity and e anthocyanins).

Algumas das principais mudanças físicas e estruturais que ocorrem durante o desenvolvimento das bagas são apresentadas na Figura 2. O incremento de massa e do tamanho da baga, na primeira fase de crescimento, estão relacionados com a divisão e expansão celular. Ambas as fases de crescimento da baga, são influenciadas pelo genótipo, pelo número de sementes, pela relação fonte-dreno (produção e partição de fotoassimilados) e pelas condições do 
meio, como por exemplo a disponibilidade hídrica (Dai et al., 2011).

Alterações importantes na circulação dos translocados ocorrem durante o desenvolvimento das bagas (Figura 2). Nas primeiras semanas de formação, há um equilíbrio entre os fluxos nos vasos de floema e xilema (Keller et al., 2006; Chatelet et al., 2008). O início da maturação marca uma mudança na funcionalidade da via de xilema, possibilitando o acúmulo de compostos químicos na baga pela manutenção na atividade do floema (Coombe e McCarthy, 2000; Ollat et al., 2002; Conde et al., 2007). Após o início da maturação, observa-se uma restrição do fluxo de água para as bagas nos feixes vasculares axiais (ou centrais) do xilema. Porém, tem sido demonstrado que muitos feixes vasculares periféricos continuam a se diferenciar mesmo após o pintor (Keller et al., 2006; Chatelet et al., 2008), que a capacidade de transporte continua sendo mantida durante a maturação, possibilitando o reaproveitamento do excesso de água do floema (Choat et al., 2009) e que a interconexão entre os vasos possibilita a manutenção do fluxo via xilema (Keller et al., 2006). Além disso, a diminuição no fluxo do xilema relatada neste período deve-se a perda da pressão hidrostática do apoplasto, como resultado da modificação do padrão de partição dos solutos (simplasto/apoplasto) ao longo do dia (Chatelet et al., 2008).

As modificações na consistência da polpa, facilmente identificadas pela deformação das bagas (Figura 2), embora evidenciado durante o início da maturação, ocorrem mais antecipadamente em nível de estrutura celular. O amolecimento da polpa envolve alterações na parede celular ocasionadas pela ação de expansinas, pectinases e outras enzimas. Embora se assuma que esses eventos estejam associados com alterações na estrutura e na composição da parede celular, a firmeza das bagas também está fortemente associada a variações na pressão de turgescência (ou turgor) das células do mesocarpo (Castellarin et al., 2016). Além disso, na epiderme das bagas, a densidade estomática é restrita e os estômatos estão recobertos pela deposição de ceras. A perda de água que ocorre por transpiração através da cutícula, diminui durante o desenvolvimento das bagas. Isso indica que a transpiração nas bagas atua como força motriz da entrada de água via xilema no início da formação das bagas, reduzindo a sua ação com o avanço da maturação (Keller et al., 2006).

A Figura 3 apresenta o possível envolvimento dos diferentes grupos hormonais durante o desenvolvimento das bagas. Na primeira fase de crescimento, os promotores de divisão e diferenciação celular atuam regulando o ciclo de formação das bagas (Conde et al., 2007; Davies e Bottcher, 2009), resultando em elevada atividade metabólica. Além das auxinas, citocininas e giberelinas, o ácido jasmônico e as poliaminas também atuam na fase de formação das bagas, sendo considerado que apresentam atividade inibitória sobre a maturação (Fortes et al., 2015). Na segunda fase de crescimento, os níveis de etileno, ácido abscísico e brassinosteroides parecem regular de forma associada e mais intensa os eventos que resultam na degradação dos ácidos orgânicos, no acúmulo de açúcares, no amolecimento das bagas, no metabolismo de compostos fenólicos e de aromas, e nas demais transformações bioquímicas (Conde et al., 2007; Fortes et al., 2015). Vários autores evidenciam a redução gradual nos níveis de etileno durante a maturação da uva, característica do padrão respiratório não climatérico (Conde et al., 2007; Davies e Bottcher, 2009; Fortes et al., 2015).

Alterações nas concentrações e no equilíbrio hormonal controlam de forma complexa cada fase do desenvolvimento das bagas, sendo que vários grupos de hormônios vegetais estão envolvidos (Robinson e Davies, 2000; Conde et al., 2007; Davies e Bottcher, 2009; Kuhn et al., 2013; Fortes et al., 2015). Possivelmente, cada evento associado à formação e maturação (amolecimento, degradação de ácidos orgânicos, acúmulo de açúcares e de compostos fenólicos, formação de aromas, entre outros) apresenta vias específicas de controle hormonal. Porém, interações diretas entre estas vias ainda carecem de evidências, impossibilitando ainda uma melhor compreensão da atuação dos hormônios durante o desenvolvimento das bagas (Fortes et al., 2015). Outros mecanismos de controle de desenvolvimento também podem estar envolvidos como sinalizadores do amadurecimento, como o acúmulo de algumas espécies reativas de oxigênio (ROS) em concentrações e compartimentos celulares específicos (Pilati et al., 2014). Estes autores verificaram o aumento na concentração de $\mathrm{H}_{2} \mathrm{O}_{2}$ no citosol das células da película no início da maturação, ocorrendo conjuntamente com o aumento do ${ }^{1} \mathrm{O}_{2}$ nos cloroplastos, atuando ao mesmo tempo, em que identificaram a peroxidação de lipídeos (galactolipídeos) de membrana.

\section{COMPOSIÇÃO DAS BAGAS}

Na Figura 4 são apresentadas algumas das principais alterações bioquímicas observadas durante 0 desenvolvimento das bagas. Após o início da maturação, ocorrem as mais importantes mudanças na composição das bagas, com o acúmulo de carboidratos simples, a redução nas concentrações de 
ácidos orgânicos (principalmente do ácido málico), a pigmentação das películas, pela formação de antocianinas e a biossíntese de muitos compostos aromáticos, como terpenos, norisoprenoides e muitos precursores de aromas (compostos glicosilados não voláteis) (Fregoni, 1999; Conde et al., 2007; Keller, 2010; Kuhn et al., 2013; Robinson et al., 2014; Gonzáles-Barreiro et al., 2015). Também muitos compostos fenólicos, como os taninos, ácidos hidroxicinâmicos e outros precursores, são sintetizados (Ali et al., 2010; Flamini et al., 2013; Kuhn et al., 2013; Teixeira et al., 2013) (Figura 5).

A uva madura (Vitis vinifera) apresenta uma das maiores concentrações de açúcares em comparação com outras frutas. Os açúcares concentrados nas bagas apresentam funções importantes nas propriedades sensoriais da uva e como fontes de precursores para a síntese de ácidos orgânicos, compostos fenólicos e aromáticos durante a maturação (Dai et al., 2011; Kuhn et al., 2013). A diversidade dos açúcares é determinada pelo genótipo, sendo predominantemente acumulada sob a forma de glicose e frutose nas variedades de Vitis vinifera, enquanto que para $V$. labrusca, $V$. rotundifolia e variedades híbridas, são encontrados teores consideráveis de sacarose (Dai et al., 2011; Cosme et al., 2016). Já a concentração de açúcares é fortemente afetada pelas práticas de manejo (raleio, manipulação do dossel, entre outros) e pelas condições do meio. É promovida pela restrição da disponibilidade hídrica, com a diminuição da temperatura, exposição à luz solar e sanidade (Kuhn et al., 2013).

A acumulação de açúcares resulta do transporte de fotoassimilados (sacarose), via floema, e posterior conversão em hexoses (glicose e frutose) pela ação de enzimas invertases (Ollat et al., 2002; Cosme et al., 2016). Com a diminuição da glicólise após o pintor, o ácido málico armazenado na primeira fase se torna a principal fonte de carbono para a respiração celular (Coombe e McCarthy, 2000; Conde et al., 2007; Gonzáles-Barreiro et al., 2015). As quantidades de glicose e frutose nas bagas apresentam aumento relativamente constante e proporção homogênea (1:1) durante a maturação, sendo preferencialmente acumulados nos vacúolos das células do mesocarpo (Cosme et al., 2016).

Os ácidos tartárico e málico representam cerca de 90\% dos ácidos orgânicos presentes nos vacúolos, ambos acumulados nas bagas durante a primeira fase de crescimento. Pequenas concentrações dos ácidos cítrico, succínico, lático e acético também estão presentes nas bagas maduras (Cosme et al., 2016). O ácido tartárico é rapidamente acumulado após a frutificação, e sua concentração vai reduzindo ligeiramente , principalmente por diluição, durante a maturação. A concentração de ácido málico atinge valores máximos próximo ao pintor e diminui intensamente após esta fase (Keller, 2010; Bobeica et al., 2015). Durante a maturação, a acumulação de potássio nas bagas resulta na formação de sais de tartarato e sais de malato, contribuindo para a redução da acidez. Embora similares, estes ácidos são sintetizados e degradados por processos bioquímicos distintos (Conde et al., 2007; Dai et al., 2011). Temperaturas mais amenas diminuem a degradação do ácido málico, resultando em maior acidez do mosto (Cosme et al., 2016). Próximo à colheita, os teores de ácido tartárico geralmente são maiores que os valores de ácido málico (Bobeica et al., 2015). O primeiro é responsável pelo sabor do vinho, contribuindo para a estabilidade biológica e longevidade, enquanto o segundo confere um sabor imaturo à fruta e paladar agressivo ao vinho (Conde et al., 2007), sendo corrigido pela fermentação malolática.

Os compostos fenólicos apresentam funções importantes na adaptação das plantas, principalmente associados às condições climáticas, e são responsáveis pela coloração, aromas e sabor da uva, afetando a cor, a estrutura, características sensoriais, gustativas e a adstringência dos vinhos (Conde et al., 2007; Teixeira et al., 2013). São encontrados preferencialmente na película das bagas (taninos e antocianinas) e nas sementes (taninos), apresentando grande variação na composição durante o desenvolvimento das bagas (Figura 5) (Kennedy et al., 2000; Adams, 2006; Conde et al., 2007; Ali et al., 2010; Guerra, 2012). Diferentes compostos fenólicos também estão presentes na polpa das uvas, porém com menor importância enológica (Teixeira et al., 2013).

A Figura 5 (abaixo) apresenta a evolução dos compostos fenólicos durante a maturação, sugerindo o momento para a colheita, quando os taninos das sementes se encontram maduros e os compostos fenólicos das películas mantém-se elevados (Ristic e Iland, 2005; Ribéreau-Gayon et al, 2006). Essas condições são resultado do potencial de extração dos compostos fenólicos, que também varia de acordo com a variedade e as condições de cultivo.

As características da uva no momento da colheita são determinadas pelas variações nas concentrações dos diferentes compostos orgânicos e minerais presentes nas bagas. Muitos desses compostos, que contribuem significativamente para os atributos sensoriais dos vinhos, são sintetizados e transformados em uma fase anterior ao início da maturação (Winkler et al., 1974; 
Kennedy et al., 2000; Adams, 2006; Conde et al., 2007; Kalua e Boss, 2010; Keller, 2010), sugerindo que o período pré-maturação também seja importante para a qualidade final da uva.

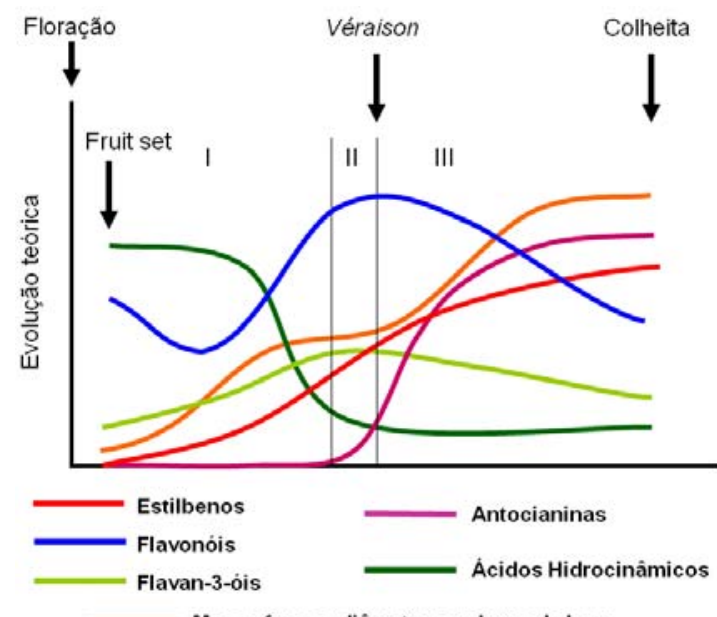

Massa fresca, diâmetro e volume da baga

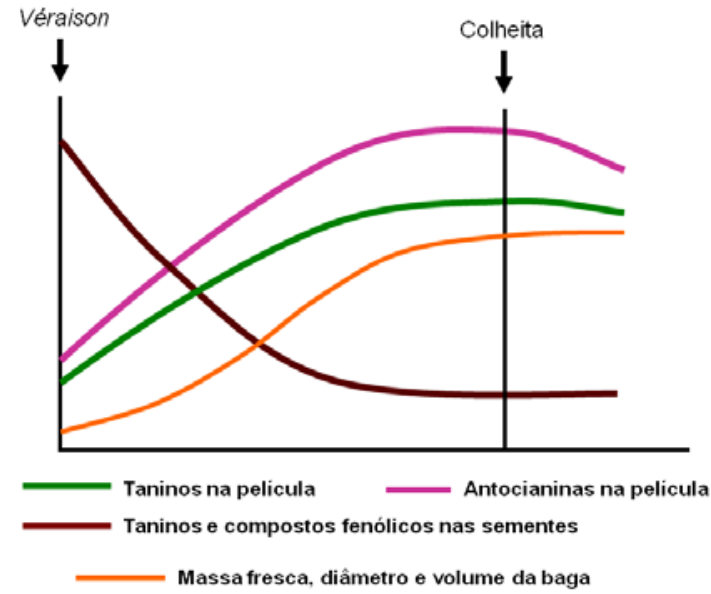

Figura 5. Alterações nos compostos fenólicos das películas durante o desenvolvimento das bagas (acima) e evolução dos taninos e antocianinas nas películas e nas sementes durante a maturação das bagas (abaixo). Elaborados a partir de Fregoni (1999) (massa fresca, diâmetro e volume), Ristic e Iland (2005) (taninos e compostos fenólicos das sementes, taninos na película, antocianinas na película), Adams (2006) (taninos das sementes, taninos na película), Ribéreau-Gayon et al. (2006) (taninos e compostos fenólicos das sementes, taninos na película, antocianinas na película) e Teixeira et al. (2013) (estilbenos, flavonóis, flavan-3-óis, antocianinas e ácidos hidroxicinâmicos).

Changes in skins phenolic compounds during berries developmen (above) and evolution of tannins and anthocyanins in skins and seeds during berries ripening (below). Elaborated from Fregoni (1999) (fresh mass, diameter and volume), Ristic e Iland (2005) (anthocyanins, total phenolics and tannins of seeds and tannins in skins), Adams (2006) (tannins of seeds and tannins in skins), Ribéreau-Gayon et al. (2006) (anthocyanins, total phenolics and tannins of seeds) e Teixeira et al. (2013) (stilbenes, flavonols, flavan-3-ols, anthocyanin and hidroxycinnamic acid)
Além destes produtos do metabolismo primário e secundário, outros compostos são encontrados e apresentam grande importância na polpa da uva. Dentre estes, podem ser citados diferentes compostos nitrogenados (aminoácidos), vitaminas, minerais em formas iônicas e não orgânicas, substâncias pécticas e diversos compostos aromáticos e metabólitos voláteis (Lund e Bohlmann, 2006; Conde et al., 2007).

As características das bagas, originadas pela diversidade e concentração dos compostos químicos, dependem do genótipo e são afetadas pelas condições do meio (clima, solo e manejo), determinando as propriedades da uva e, consequentemente, os atributos sensoriais dos vinhos (Winkler et al., 1974; Fregoni, 1999; Ribéreau-Gayon et al, 2006; Keller, 2010). Essas condições particulares expressam o que se identifica como terroir, "imprimindo" um registro particular e que possibilita o reconhecimento de condições distintas, como uma variedade ou mesmo uma região de produção.

\section{MATURAÇÃO DAS BAGAS}

A maturação dos frutos é um processo coordenado, complexo e dinâmico. Assim, as relações entre as variáveis analisadas na uva podem ser utilizadas como indicativos do nível de maturação das bagas e/ou para o estabelecimento do momento da colheita (Winkler et al., 1974; Coombe e McCarthy, 2000; Kennedy et al., 2000; Ollat et al., 2002; Ristic e Iland, 2005; Guerra, 2012). Diferentemente da frutificação e do pintor (véraison), a colheita não constitui um estádio fenológico. Diferentes níveis de maturação das bagas podem ser distinguidos num mesmo cacho, ou também em diferentes partes da baga (Ribéreau-Gayon et al., 2006). Também, dependendo do processo de vinificação, das características qualitativas desejadas e das condições meteorológicas e sanitárias, a colheita pode ser antecipada ou atrasada. Bindon et al. (2013) observaram grandes variações na composição química do mosto e nos compostos fenólicos das películas e sementes ao avaliarem a colheita da Cabernet Sauvignon em diferentes níveis de maturação. Estes autores identificaram diferenças significativas nos atributos químicos e nas concentrações de compostos voláteis dos vinhos. Estes resultados demonstraram que a matriz química dos vinhos foi influenciada principalmente pelo nível de maturação da uva e, secundariamente, pelo metabolismo fermentativo em resposta à concentração de açúcares do mosto.

Os cachos são formados por um conjunto de frutos, onde os processos bioquímicos não estão em total sincronia, dependendo da posição das bagas (Robinson e Davies, 2000; Tarter e Keuter, 2005; 
Pagay e Cheng, 2010). Estes autores descrevem variações importantes nas concentrações de açúcares e ácidos orgânicos das bagas. Alterações na concentração de antocianinas foram determinadas dependendo da posição das bagas (apical, mediana e basal) e da exposição (externa e interna) no cacho (Pisciotta et al., 2013). Estes autores também observaram variações nos teores de antocianinas em diferentes partes da película de uma mesma baga. Variações importantes na diversidade e na concentração de compostos aromáticos também foram descritas em bagas localizadas em diferentes posições no cacho (Gonzáles-Barreiro et al., 2015). Assim, uma amostragem aceitável (cerca de 200 bagas) durante o desenvolvimento, coletando bagas de todas as posições dos cachos e de diferentes ramos e em várias plantas possibilita diminuir erros e avaliar as alterações físicas e a composição química de forma mais precisa (Tarter e Keuter, 2005; Pagay e Cheng, 2010; Guerra, 2012).
O acompanhamento da evolução nos teores de açúcares e de ácidos orgânicos na polpa das bagas (maturação tecnológica) é um dos indicadores mais utilizados para estabelecer a data de colheita da uva (Winkler et al., 1974; Fregoni, 1999; Coombe e McCarthy, 2000; Kennedy et al., 2000; RibéreauGayon et al., 2006; Keller, 2010). Porém, estas análises podem não expressar o ótimo ponto de maturação, sendo a avaliação dos compostos fenólicos (principalmente taninos e antocianinas) também utilizada para definir com maior precisão o momento de colheita (Conde et al., 2007; Guerra, 2012). Os compostos fenólicos podem ser divididos em dois grupos, os flavonóides, que são os mais abundantes na uva, e os não flavonóides (Figura 6). As antocianinas, as proantocianidinas (flavan-3-ois ou taninos condensados) e os flavonóis são os principais exemplos de compostos flavonóides. Os principais compostos não flavonóides são os estilbenos, e os ácidos hidroxicinâmicos e hidroxibenzóicos (Teixeira et al., 2013).

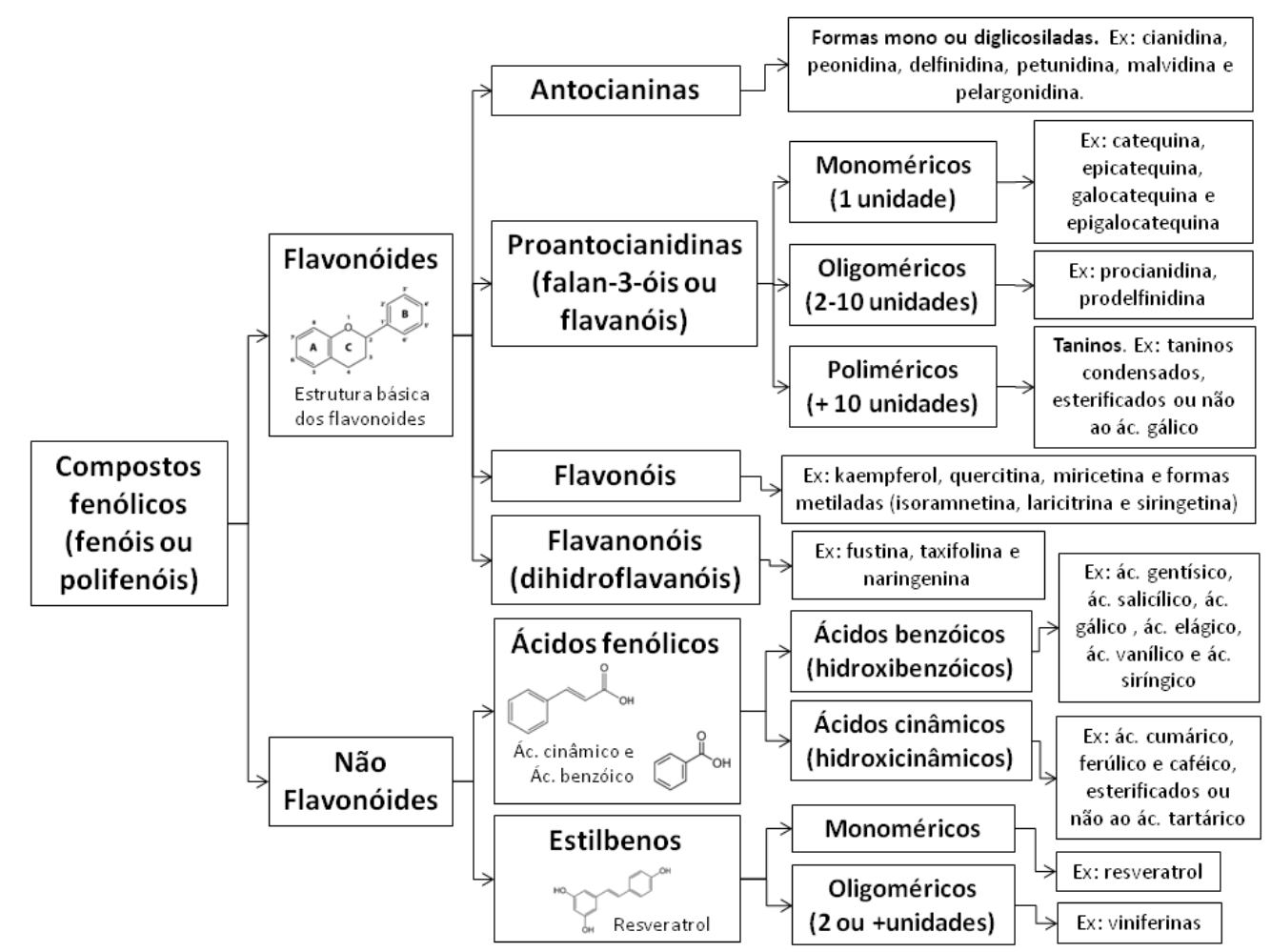

Figura 6. Diferentes classes de compostos fenólicos presentes na uvas e vinhos. Elaborado a partir de Adams (2006), Ribéreau-Gayon et al. (2006), Guerra (2012), Flamini et al. (2013) e Teixeira et al. (2013).

Different classes of phenolic compounds present in grapes and wines. Elaborated from Adams (2006), Ribéreau-Gayon et al. (2006), Guerra (2012), Flamini et al. (2013) and Teixeira et al. (2013). 
A avaliação da composição fenólica agrega a quantificação dos teores de antocianinas e taninos das películas e sementes, para complementar as análises de maturação tecnológica (evolução dos açúcares e da acidez). Essas avaliações podem servir para a caracterização tanto qualitativa da uva, quanto do potencial da região (Guerra, 2012). A evolução dos compostos fenólicos progride de forma muito diferente dependendo dos grupos químicos analisados e geralmente o máximo de concentração não coincide com o maior teor de açúcares na baga (Ristic e Iland, 2005; Ribéreau-Gayon et al., 2006; Teixeira et al., 2013). A maturação fenólica abrange não apenas a concentração das substâncias pertencentes a esta família de compostos, mas também a estrutura química e a sua evolução, alterando a capacidade de extração nas diferentes partes da baga durante o processo de vinificação (Ribéreau-Gayon et al., 2006). Assim, a maturação fenólica pode ser compreendida como a evolução da diversidade, da concentração e da estabilidade dos compostos fenólicos durante o período de maturação das bagas.

Além da maturação tecnológica e fenólica, a maturação aromática também é importante do ponto de vista qualitativo, sendo estabelecida pela degustação das bagas, avaliando a relação entre os compostos agradáveis e desagradáveis (aromas herbáceos). Embora todas se apresentem como variáveis independentes durante a maturação da uva, ambas devem ser consideradas para a definição do momento de colheita e na busca da melhor qualidade enológica (Ribéreau-Gayon et al., 2006).

Os taninos são a classe mais abundante de compostos fenólicos solúveis encontrados na uva, localizando-se nas camadas hipodérmicas das películas e no tegumento das sementes (Ristic e Iland, 2005; Adams, 2006). O termo tanino se refere a uma denominação genérica. No limite da viticultura e enologia, tanino é designado para as substâncias (flavan-3-óis, flavonóis e flavanonóis) que tem a propriedade de reagir fortemente com proteínas e que contribuem para a estabilização dos vinhos (Guerra, 2012). Apresentam ação fotoprotetora à radiação UV (Flamini et al., 2013) e estão localizados nos vacúolos e na parede celular (Teixeira et al., 2013). Os taninos das películas possuem estruturação complexa e variação nos níveis de polimerização. Durante a maturação, as propriedades coloidais tendem a diminuir, resultando em menor agressividade e adstringência (Ribéreau-Gayon et al, 2006).

As antocianinas constituem os pigmentos localizadas essencialmente na película, sendo estocadas nos vacúolos ou em vesículas no citoplasma (antocianoplastos). Em algumas variedades tintórias, podem ser encontradas também na polpa (Teixeira et al., 2013). Também podem estar presentes nas folhas no final do ciclo vegetativo (Ribéreau-Gayon et al, 2006), além de diferentes órgãos como pedicelo, ráquis e brotos (Kuhn et al., 2013). Existem cinco antocianinas presentes na uva: cianidina, peonidina, delfinidina, petunidina e malvidina, com esta última em maior concentração (Ribéreau-Gayon et al, 2006). Flamini et al. (2013) e Kuhn et al. (2013) também descrevem a presença da pelargonidina para $V$. vinifera. Nas uvas tintas, as antocianinas estão na forma de mono e diglicosídeos. O monoglicosídeo de malvidina é o constituinte principal da matéria corante de $V$. vinifera. O diglicosídeo de malvidina é encontrado nas uvas de origem americana ( $V$. labrusca e outras espécies) e em alguns híbridos (Guerra, 2012; Teixeira et al., 2013). A temperatura apresenta importância sobre a síntese de antocianinas, sendo que em regiões frias, a concentração é menor, enquanto vinhedos cultivados até $35^{\circ} \mathrm{C}$ e com grande amplitude térmica, apresentam condições mais favoráveis, originando vinhos com mais cor (Ribéreau-Gayon et al., 2006). A radiação solar é o fator que mais impacta a formação de antocianinas, sendo a concentração destes compostos favorecida pelo aumento da exposição à luz, principalmente em resposta à radiação UV (Teixeira et al., 2013).

Os teores de compostos fenólicos variam com a variedade, estágio de maturação, vigor vegetativo, práticas de manejo e fatores climáticos, como a luz e a temperatura (Obreque-Slier et al., 2010; Flamini et al., 2013). Após o início da maturação da uva, o teor de compostos fenólicos das películas aumenta, enquanto os teores de taninos nas sementes vão diminuindo (Figura 4 e 5) (Adams, 2006; ObrequeSlier et al., 2010). Várias pesquisas demonstram que os teores de polifenóis e, de modo especial de taninos, estão diretamente relacionados com as condições climáticas (Adams, 2006; Conde et al., 2007; Kuhn et al., 2013; Teixeira et al., 2013). Outros compostos fenólicos como alguns ácidos fenólicos e estilbenos, normalmente são acumulados durante a maturação das bagas, principalmente em respostas aos estresses biótico ou abiótico (Teixeira et al., 2013). Alguns compostos fenólicos voláteis presentes nas películas estão envolvidos nos aromas primários que se desenvolvem durante a maturação das bagas (Conde et al., 2007).

Os compostos aromáticos pertencem a um grupo grande de moléculas voláteis que podem ser identificadas nas uvas e nos vinhos (Figura 7). Esses compostos químicos estão relacionados com atributos sensoriais associados a características aromáticas como flores, frutas, vegetais, especiarias, produtos tostados, entre outros (Ribéreau-Gayon et al., 2006; 
Robinson et al., 2014; Gonzáles-Barreiro et al., 2015). Podem ser divididos em três grupos: compostos aromáticos voláteis ou livres (terpenoides e pirazinas), os compostos precursores não voláteis (glicosídeos, ácidos fenólicos, ácidos graxos, entre outros) e os compostos aromáticos não voláteis (terpenoides glicosilados, norisoprenoides glicosilados, entre outros) (Ribéreau-Gayon et al, 2006; Gonzáles-Barreiro et al., 2015). Esses autores descrevem que os compostos aromáticos apresentam a maior importância na qualidade e particularidade (varietal ou regional) dos vinhos, em comparação com outros componentes químicos da uva.

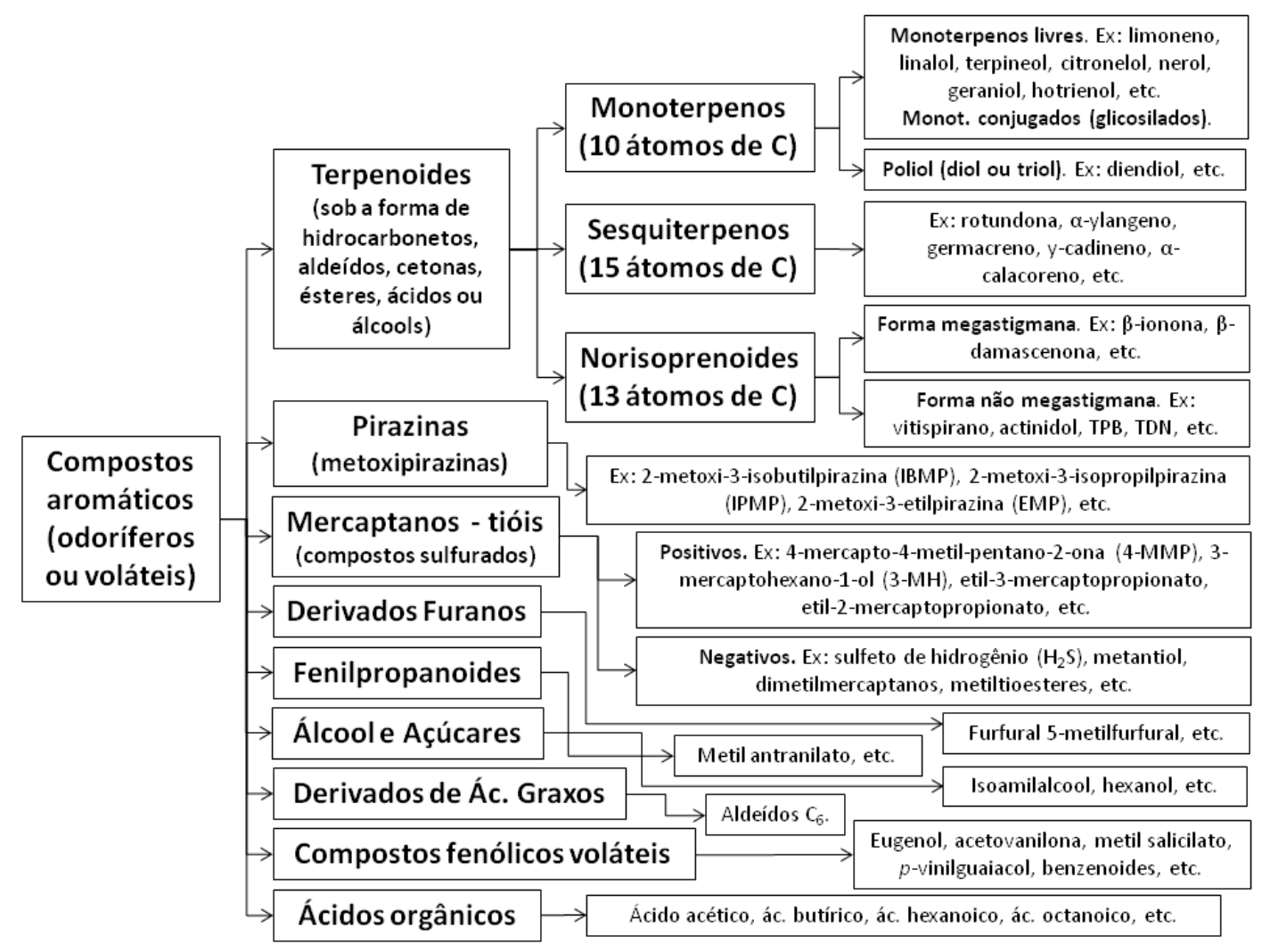

Figura 7. Diferentes classes de compostos aromáticos presentes na uvas e vinhos. Elaborado a partir de Ribéreau-Gayon et al. (2006), Sun et al. (2011), Robinson et al. (2014), Fortes et al. (2015), Gonzales-Barreiro et al. (2015) e Ilc et al. (2016).

Different classes of aromatic compounds present in grapes and wines. Elaborated from Ribéreau-Gayon et al. (2006), Sun et al. (2011), Robinson et al. (2014), Fortes et al. (2015), Gonzales-Barreiro et al. (2015) and Ilc et al. (2016).

Dentre os principais grupos de compostos aromáticos, destacam-se os terpenoides, com dezenas de compostos que apresentam aromas de frutas e florais. Entre os cerca de 4000 terpenoides, aproximadamente 40 foram identificados para as uvas. Possuem destaque nos atributos sensoriais de muitos vinhos e impacto sinérgico (Ribéreau-Gayon et al., 2006; Gonzáles-Barreiro et al., 2015), ou seja, resultante da combinação do efeito dos diferentes compostos (concentração e diversidade) presentes na uva. Os monoterpenoides estão associados a aromas florais e de frutas, e contribuem significativamente para a composição aromática de variedades moscatéis (como a 'Moscato de Alexandria') e não moscatéis (como a
'Gewurztraminer' e a 'Riesling'), estando presentes também em variedades neutras (como 'Cabernet Sauvignon', 'Merlot', 'Sauvignon Blanc' e 'Chardonnay') (Conde et al., 2007; Robinson et al., 2014).

Os norisoprenoides, compostos derivados dos carotenoides, que assim como muitos monoterpenos, estão presentes sob formas de glicosídeos não voláteis na uva, sendo liberados apenas durante o processo de vinificação. Muitos carotenoides presentes na uva ( $\beta$ caroteno, luteína, neocromo, neoxantina, violaxantina, luteoxantina, flavoxantina e zeaxantina) são acumulados na película da uva antes do início da maturação, sendo posteriormente biodegradados por 
ação enzimática a precursores aromáticos e em seguida convertidos a compostos aromáticos ativos (Robinson et al., 2014). Muitos norisoprenoides também estão associados a aromas de frutas ou de flores. Em geral, o acúmulo de compostos voláteis como os monoterpenos, sesquiterpenos e C-13 norisoprenoides ocorre após o pintor (Carlomagno et al., 2016). Estes autores também destacaram que os compostos voláteis sob a forma livre são derivados de metabolitos lipídicos e que apresentam uma importante contribuição para a composição aromática varietal.

As metoxipirazinas são compostos nitrogenados originados do metabolismo de aminoácidos, sendo associadas com características vegetais. Dentre os compostos químicos aromáticos, as pirazinas, em geral, apresentam uma dualidade sensorial, estando associadas a aromas de pimenta, aspargo ou ervilhas. Em baixas concentrações contribuem positivamente para as características varietais ('Cabernet Sauvignon', 'Sauvignon Blanc', 'Carmenére', entre outras), porém, em elevadas concentrações são consideradas indesejáveis (Robinson et al., 2014; Gonzáles-Barreiro et al., 2015; Ilc et al., 2016). Esses compostos são acumulados nas bagas desde a fase inicial de desenvolvimento, atingindo maiores concentrações antes do pintor, apresentando redução expressiva durante a maturação (Zhu et al., 2012).

Muitos compostos voláteis sulfurados com função tiol (mercaptanos) causam aromas negativos aos vinhos (ovo em decomposição), enquanto outros contribuem positivamente, sendo associados com frutas, aromas mineral, de produtos tostados, entre outros (Kuhn et al., 2013; Robinson et al., 2014; Gonzáles-Barreiro et al., 2015; Ilc et al., 2016). Os fenilpropanoides voláteis contribuem tanto em variedades brancas quanto em uvas viníferas tintas, sendo especialmente importante no aroma "foxado" (antranilato de metila), característico de uvas americanas e híbridas (Vitis labrusca) (Wang e Luca, 2005; Robinson et al., 2014; Gonzáles-Barreiro et al., 2015; Ilc et al., 2016). O 2aminoacetofenona (2AAP) (aroma "foxado") e o furaneol (aromas de caramelo e morango) são outros compostos característicos de aromas de uvas americanas e híbridas e possivelmente associados a uvas muscadíneas (Vitis rotundifolia) (Sun et al., 2011).

Em particular, o termo "foxy” (raposa, do inglês) refere-se a uma descrição abrangente e única, associada a características particulares, de aroma e sabor adocicados, que são percebidas em uvas frescas nativas da América do Norte, principalmente na variedade 'Concord', mas também em outras variedades de $V$. labrusca e de outras espécies
(Winkler et al., 1974). Essa palavra tem sido usada desde 1622 na descrição das uvas que apresentavam sabor muito doce e que produziam vinhos de coloração intensa. Há diversas teorias que tentam justificar o uso deste termo, como aquelas que associam a palavra a um significado distinto do animal (raposa), como uma distorção da palavra faux que significa "falso", ou uma associação com a possibilidade de "intoxicação" pelo consumo dos vinhos de labruscas. Outras teorias relacionam a forma ou pilosidade das folhas com o formato da pata ou presença lã do animal. Há ainda outras que associam o comportamento das raposas, no qual, as uvas eram os alimentos preferidos, ou em outra hipótese, onde o odor intenso dos animais é associado ao aroma pronunciado das uvas maduras. A mais recente teoria sugere que este termo foi usado para indicar que essas uvas estão associadas à videiras selvagens (Pinney, 1989). Há muitas controvérsias na justificativa real da utilização do termo foxy, que não deve ser entendido como depreciativo de qualidade, mas sim na definição de um conjunto de características marcantes, presentes em alguns grupos de uvas. O aroma "foxado" é formado pelo acúmulo desses compostos aromáticos durante a maturação das bagas, sob a forma livre e volátil, atribuindo aroma e sabor peculiar as uvas labruscas (Keller, 2010).

Outros compostos como os derivados furanos, derivados de ácidos graxos, contribuem com aromas tostados e de caramelo, e aromas vegetais ou "verdes”, respectivamente. Voláteis derivados de açúcares e de aminoácidos e ácidos orgânicos, ésteres e alcoóis superiores também apresentam importância na composição aromática dos vinhos (Robinson et al., 2014; Gonzáles-Barreiro et al., 2015; Ilc et al., 2016).

Em relação à composição aromática, o termo “aroma varietal” não implica que cada variedade apresente compostos voláteis específicos, mas sim está associado à combinação dos vários grupos e formas químicas existentes, resultando em uma personalidade individual ou de um grupo de variedades (RibéreauGayon et al., 2006; Gonzáles-Barreiro et al., 2015). O aroma de um vinho é formado por uma complexa mistura de compostos orgânicos voláteis, classificados a partir de três categorias: os aromas da uva (primários), aromas originados da fermentação (secundários) e os aromas do processo de armazenamento ou envelhecimento (terciários). Temse identificado muitos precursores de aromas originados das uvas e que são alterados apenas durante o processo de vinificação ou envelhecimento (Robinson et al., 2014; Ilc et al., 2016). Além disso, a complexidade de aromas nos vinhos também se deve à diversidade de mecanismos envolvidos na sua formação, como a composição da uva, as 
modificações bioquímicas antes da fermentação, as mudanças químicas decorrentes da interação com os microorganismos envolvidos nas fermentações (alcoólica e malolática) e as reações químicas ou enzimáticas nos tanques, barris e garrafas (Conde et al., 2007; Styger et al., 2011), além das associadas ao armazenamento e envelhecimento (Styger et al., 2011; Robinson et al., 2014). Aromas terciários são formados em muitas situações, a partir de rearranjos entre ácidos e álcoois durante o envelhecimento. Neste sentido, o termo francês bouquet é utilizado para caracterizar olfativamente o vinho maduro, a partir da complexidade de transformações aromáticas ocorridas após a vinificação e o envelhecimento (Robinson et al., 2014).

Os compostos aromáticos localizados preferencialmente na polpa e na película, podem ser encontrados tanto em formas livres quanto conjugadas (glicosiladas) (Conde et al., 2007; Gonzáles-Barreiro et al., 2015). Enquanto as metoxipirazinas são sintetizadas durante a formação das bagas, iniciando a degradação no início da maturação, a biossíntese de muitos compostos orgânicos voláteis como os terpenoides e norisoprenoides ocorre durante a maturação das bagas (Lund e Bohlmann, 2006; Gonzáles-Barreiro et al., 2015) (Figura 8).

A acumulação dos compostos fenólicos e compostos aromáticos durante o desenvolvimento das bagas varia intensamente, dependendo dos grupos químicos. As condições meteorológicas afetam a expressão de genes associados ao metabolismo de fenilpropanóides, particularmente no início da maturação (Robinson et al., 2014). Esses metabólitos secundários estão associados tanto à formação de compostos aromáticos, quanto de compostos fenólicos voláteis e não voláteis. Ambos os compostos podem afetar isoladamente e em conjunto a percepção dos atributos sensoriais dos vinhos (Holt et al., 2008; Lund et al., 2009).

\section{MATURAÇÃO DAS SEMENTES}

A formação das sementes envolve três processos fisiológicos: o crescimento, a acumulação de reservas (como lipídeos, proteínas e amido) e a fase de início da dormência. Em cada uma destas etapas, há alterações estruturais e na composição química das sementes. Nas sementes maduras, o tegumento possui a função de proteção mecânica para o embrião e ajuda na manutenção da dormência da semente (Ristic e Iland, 2005). As mudanças nos taninos e demais compostos fenólicos das sementes durante a maturação são intensamente percebidas nos atributos sensoriais das uvas e nas características gustativas dos vinhos (Fredes et al., 2010).

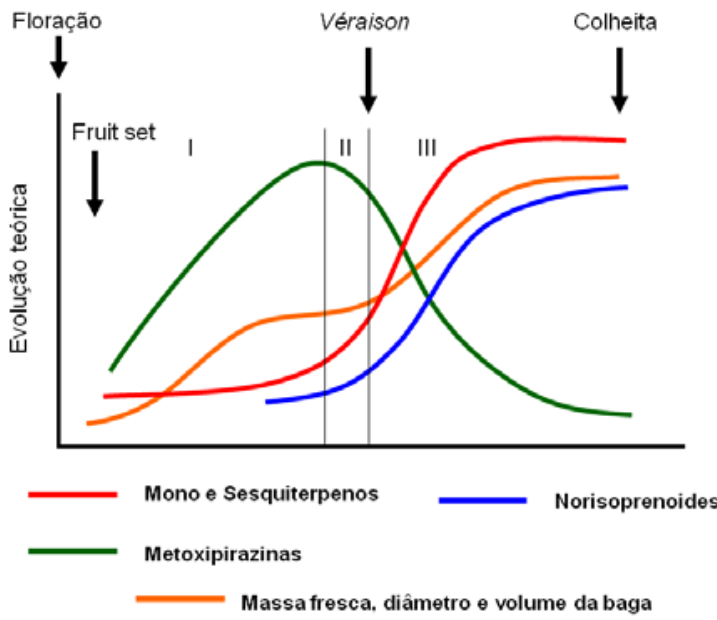

Figura 8. Alterações nos compostos aromáticos durante o desenvolvimento das bagas (direita). Elaborados a partir de Fregoni (1999) (massa fresca, diâmetro e volume), Ribéreau-Gayon et al. (2006) (mono e sesquiterpenos, norisoprenoides e metoxipirazinas), Keller (2010) (metoxipirazinas), Zhu et al. (2012)

(metoxipirazinas), Kuhn et al. (2013) (mono e sesquiterpenos, norisoprenoides e metoxipirazinas), Robinson et al. (2014) (mono e sesquiterpenos e metoxipirazinas), Gonzáles-Barreiro et al. (2015) (mono e sesquiterpenos e norisoprenoides).e Carlomagno et al. (2016) (mono e sesquiterpenos e norisoprenoides).

Changes in aromatic compounds during berries development (right). Elaborated from Fregoni (1999) (fresh mass, diameter and volume), Ribéreau-Gayon et al. (2006) (mono and sesquiterpenes, norisoprenoids and methoxypyrazines), Keller (2010)

(methoxypyrazines), Zhu et al. (2012) (methoxypyrazines), Kuhn et al. (2013) (mono and sesquiterpenes, norisoprenoids and methoxypyrazines), Robinson et al. (2014) (mono and

sesquiterpenes and methoxypyrazines), Gonzáles-Barreiro et al. (2015) (mono and sesquiterpenes and norisoprenoids) $e$ Carlomagno et al. (2016) (mono and sesquiterpenes and norisoprenoids).

À medida que a formação das bagas avança, a coloração do tegumento das sementes se altera, sendo possível identificar o escurecimento de forma simples e fácil a partir do início da maturação (Figura 9). Essa transformação visual é resultado da lignificação dos tecidos e da oxidação dos compostos fenólicos, que ocorre no período de maturação (Kennedy et al., 2000; Ristic e Iland, 2005; Cadot et al., 2006). As mudanças na aparência das sementes que ocorram durante a formação e maturação da uva podem ser facilmente visualizadas em muitas variedades. Porém, para alguns grupos de uvas viníferas, como a 'Carménère' (Fredes et al., 2010), a 'Sangiovese' e outras variedades, a coloração mais escura desde as fases iniciais de formação das sementes, dificulta esta avaliação, necessitando de escalas ajustadas de coloração (Figura 9 direita). Possivelmente esta variação no padrão de coloração das sementes deve-se 
ao ciclo mais longo associado a diferenças na evolução da composição fenólica das sementes
(Fredes et al., 2010).
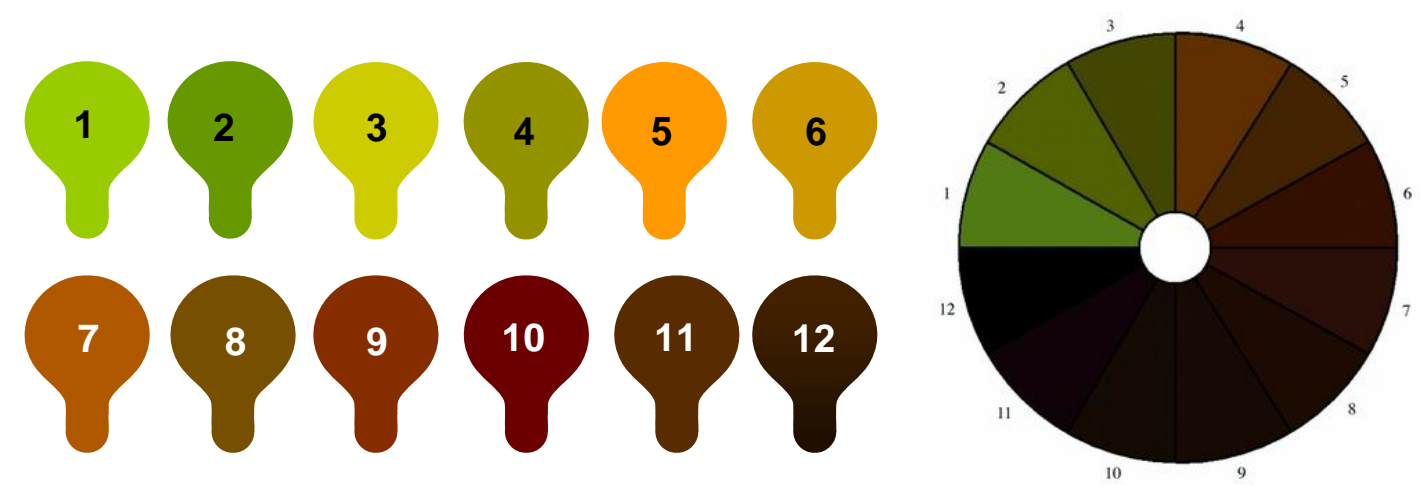

Figura 9. Escalas de coloração das sementes de uva durante o desenvolvimento e maturação das bagas (1 a 12). Escala adaptada de Ristic e Iland (2005) (esquerda) e escala elaborada por Fredes et al. (2010) (direita).

Scales of grape seeds color during development and ripening of berries (1 to 12). Scale adapted from Ristic and Iland (2005) (left) and scale elaborated by Fredes et al. (2010) (right).

Os principais compostos fenólicos solúveis presentes nas sementes são os taninos, além da presença menos expressiva de formas monoméricas de flavan-3-ois (Adams, 2006). A síntese dos taninos nas sementes ocorre na primeira fase de desenvolvimento, com as bagas verdes, atingindo valores máximos próximo ao pintor (Ristic e Iland, 2005; Adams, 2006). A concentração de todos os compostos fenólicos das sementes reduz-se drasticamente durante a maturação das bagas (Kennedy et al., 2000). A partir do início da maturação, os níveis de polimerização dos taninos diminuem, aumentando a taxa de reatividade às proteínas (Kennedy et al., 2000; Fredes et al., 2010).

A colheita das uvas pode ser determinada através da avaliação sensorial das uvas (Ribéreau-Gayon et al., 2006). A análise da cor e a degustação das sementes são critérios utilizados para o estabelecimento do momento da colheita (Fredes et al., 2010). Estes autores também afirmaram que a baixa presença de taninos, a coloração escura e a facilidade de separação entre a polpa e as sementes são as características mais facilmente identificados. Ristic e Iland (2005) descreveram que a maturação das sementes é definida quando atingem a máxima massa seca e o mínimo de taninos solúveis. Assim, estes autores consideram que uma baga madura é caracterizada por películas ricas e complexas em antocianinas (variedades tintas) e com taninos relativamente inativos, além de sementes com baixo teor de taninos polimerizados.

A escala de coloração das sementes estabelecida por Ristic e Iland (2005) define como verde-amarelo (14) o estádio de formação das bagas, amarelo (5) o estádio próximo ao início da maturação, marron-claro (6-9) para o período de maturação e marrom-escuro (10-12) para uma condição mais favorável para a colheita. No caso da escala proposta por Fredes et al. (2010), observa-se coloração escura mais intensa das sementes já a partir do início da maturação (6). Em ambos os casos, a análise visual da coloração das sementes é realizada para determinar as mudanças durante a evolução da maturação. Fredes et al. (2017) utilizaram um modelo de análise de imagens escaneadas de sementes, quantificando as mudanças de coloração através de um software. Considerando a composição química das bagas, estes autores classificaram a maturação das sementes em três estágios de acordo com a coloração das sementes, definindo as sementes imaturas (marrom com traços verdes), maduras (marrom escuro com pequenos traços verdes) e sobremaduras (marrom escuro). Este estudo ainda identificou que tanto a avaliação realizada a partir da visão humana quanto aquela efetuada através de computadores tem a capacidade de reconhecer as variações de coloração verde durante a maturação das sementes.

Correlações significativas entre a coloração das sementes e a maturação comercial (açúcares e acidez), e com a maturação fenólica foram observadas por Ristic e Iland (2005), Fredes et al. (2010) e Fredes et al. (2017). Estes autores também verificaram relação entre a coloração e a redução nos teores de taninos das sementes e o aumento nas concentrações de antocianinas e de polifenóis totais nas películas. Essas relações entre a coloração das sementes e a concentração de taninos solúveis ou 
outros índices de maturação sugerem que esta análise pode ser utilizada como um indicador da maturidade das sementes (Ristic e Iland, 2005; Fredes et al., 2017). De forma mais ampla, a avaliação da cor das sementes também pode ser uma ferramenta rápida e complementar para a determinação do momento de colheita.

\section{CONSIDERAÇÕES FINAIS}

Importantes avanços na compreensão dos processos envolvidos na formação e maturação das bagas foram discutidos. A composição da uva se altera constantemente, tanto durante o avanço dos estádios fenológicos, quanto em resposta aos diferentes fatores do meio que atuam sobre a videira. Uma grande complexidade de processos regula e modifica

\section{REFERÊNCIAS BIBLIOGRÁFICAS}

Adams D.O., 2006. Phenolics and ripening in grape berries. Am. J. Enol. Viticult., 57, 249-256.

Ali K., Maltese F., Choi Y.H., Verpoorte R., 2010. Metabolic constituents of grapevine and grape-derived products. Phytochem. Rer., 9, 357-378.

Barata A., Malfeito-Ferreira M., Loureiro V., 2012. The microbial ecology of wine grape berries. Int. J. Food Microbiol., 153, 243259.

Bindon K., Varela C., Kennedy J, Holt H., Herderich M., 2013. Relationships between harvest time and wine composition in Vitis vinifera L. cv. Cabernet Sauvignon: 1. Grape and wine chemistry. Food Chem., 138, 1696-1705.

Bobeica N., Poni S., Hilbert G., Renaud C., Gomès E., Delrot S., Dai Z., 2015. Differential responses of sugar, organic acids and anthocyanins to source-sink modulation in Cabernet Sauvignon and Sangiovese grapevines. Front. Plant Sci., 6, 1-14.

Bokulich N.A., Thorngate J.H., Richardson P.M., Mills D.A., 2013. Microbial biogeography of wine grapes is conditioned by cultivar, vintage, and climate. PNAS, 25, 139-148.

Bondada B.R., Keller M., 2012. Not all shrivels are created equalmorpho-anatomical and compositional characteristics differ among different shrivel types that develop during ripening of grapes (Vitis vinifera L.) berries. Am. J. Plant Sci., 3, 879-898.

Cadot Y., Miñana-Castelló M.T., Chevalier M., 2006. Anatomical, histological, and histochemical changes in grape seeds from Vitis vinifera L. cv Cabernet Franc during fruit development. J. Agric. Food Chem., 54, 9206-9215.

Carlomagno A., Schubert A., Ferrandino A., 2016. Screening and evolution of volatile compounds during ripening of 'Nebbiolo', 'Dolceto' and 'Barbera' (Vitis vinifera L.) neutral grapes by SBSEGC/MS. Eur. Food Res. Technol., 242, 1221-1233.

Castellarin S.D., Gambetta G.A., Wada H., Krasnow M.N., Cramer G.R., Peterlunger E., Shackel K.A., Matthews M.A., 2016. Characterization of major ripening events during softening in grape: Turgor, sugar accumulation, abscisic acid metabolism, colour development, and their relationship with growth. J. Exp. Bot., 67, 709-722. a concentração e a diversidade de compostos químicos nas diferentes partes da baga. $\mathrm{O}$ acompanhamento da maturação tecnológica, fenólica, aromática e das sementes possibilita uma avaliação mais completa das características da uva destinada ao processo de vinificação. Esse metabolismo é o responsável pelas características particulares da uva em cada condição de cultivo e que influenciam as propriedades químicas e sensoriais dos vinhos durante a fermentação e após o envelhecimento.

\section{AGRADECIMENTOS}

O autor agradece à Coordenação de Aperfeiçoamento de Pessoal de Nível Superior - CAPES pela bolsa de pós-doutorado.

Chatelet D.S., Rost T.L., Shackel K.A., Matthews M.A., 2008. The peripheral xylem of grapevine (Vitis vinifera) berries. 1. Structural integrity in post-veraison berries. J. Exp. Bot., 59, 1987-1996.

Choat B., Gambetta G.A., Shackel K.A., Matthews M.A., 2009. Vascular function in grape berries across development and its relevance to apparent hydraulic isolation. Plant Physiol., 151, 1677-1687.

Conde C., Fontes N., Dias A.C.P., Tavares R.M., Souza M.J., Agasse A., Delrot S., Gerós H., 2007. Biochemical changes throughout grape berry development and fruit and wine quality. Food, 1, 1-22.

Coombe B.G., Mccarthy M.G., 2000. Dynamics of grape berry growth and physiology of ripening. Aust. J. Grape Wine R., 6, 131135.

Cosme F., Gonçalves B., Inês A., Jordão A.M., Vilela A., 2016. Grape and wine metabolites: biotechnological approaches to improve wine quality. In: Grape and wine biotechnology. 187-224. Morata A., Loira I. (eds.), INTECH, Rijeka/Croacia.

Dai Z.W., Ollat N., Gomès E., Decroocq S., Tandonnet J.P., Bordenave L., Pieri P., Hilbert G., Kappel C., Leeuwen C., Vivin P., Delrot S., 2011. Ecophysiological, genetic, and molecular causes of variation in grape berry weight and composition: a review. Am. J. Enol. Vitic., 62, 413-425.

Davis C., Bottcher C., 2009. Hormonal control of grape berry ripening. In: Grapevine molecular physiology \& biotechnology. 229-261. Roubelakis-Angelis K.A. (ed.), Springer Science, 2nd edition.

Dokoozlian N.K., 2000. Chapter 5: Grape berry growth and development. In: Raisin production manual. 30-37. Cristensen L.P., (ed.). University of California, 1nd. edition.

Flamini R., Mattivi F., Rosso M., Arapitsas P., Bavaresco L., 2013. Advanced knowledge of three important classes of grape phenolics: anthocyanins, stilbenes and flavonols. Int. J. Mol. Sci., 14, 1965119669.

Fortes A.M., Teixeira R.T., Agudelo-Romero P., 2015. Complex interplay of hormonal signals during grape berry ripening. Molecules, 20, 9326-9343. 
Fredes C., Bennewitz E.V., Holzapfel E., Saavedra F., 2010. Relation between seed appearance and phenolic maturity: a case study using grapes cv. Carménère. Chilean J. Agr. R., 70, 381-389.

Fredes C., Mora M., Carrasco-Benavides M., 2017. Na analysis of seed colour during ripening of Cabernet Sauvignon grapes. S. Afr. J. Enol. Vitic., 38, 38-45.

Fregoni M., 1999. Viticoltura di qualità. 705 p. Piacenza, 2ª ed.

Gilbert J.A., Lelie D.V., Zarraonaindia I., 2014. Microbial terroir for wine grapes. PNAS, 111, 5-6.

González-Barreiro C., Rial-Otero R., Cancho-Grande B., SimalGárdara J., 2015. Wine aroma compounds in grapes: A critical review. Crit. Rev. Food Sci., 55, 202-218.

Guerra C.C., 2012. Polifenóis da uva e do vinho. Rev. Bras. Viticult. Enol., 4, 90-100.

Holt H.E., Francis I.L., Field J., Herderich M.J., Iland P.G., 2008. Relationships between wine phenolic composition and wine sensory properties for Cabernet Sauvignon (Vitis vinifera L.). Aust. J. Grape Wine R., 14, 162-176.

Ilc T., Werck-Reichhart D., Navrot N., 2016. Meta-analysis of the core aroma components of grape and wine aroma. Front. Plant Sci., 7, $1-15$

Kalua C.M., Boss, P.K., 2010. Comparison of major volatile compounds from Riesling and Cabernet Sauvignon grapes (Vitis vinifera L.) from fruitset to harvest. Aust. J. Grape Wine R., 16, 337-348.

Keller M., 2010. The Science of grapevines. Anatomy and Physiology. 368p. Elsevier, Academic Press, Burlington.

Keller M., Smith J.P., Bondada B.R., 2006. Ripening grape berries remain hydraulically connected to the shoot. J. Exp. Bot., 57, 25772587

Kennedy J.A., Matthews M.A., Waterhouse A.L., 2000. Changes in grape seed polyphenols during fruit ripening. Phytochem., 55, 7785.

Kuhn N., Guan L., Dai Z.W., Wu B., Lauvergeat V., Gomès E., Li S., Godoy F., Arce-Johnson P., Delrot S., 2013. Berry ripening: recently heard through the grapevine. J. Exp. Bot., 65, 4543-4559.

Lund S.T., Bohlmann J., 2006. The molecular basis for wine grape quality - a volatile subject. Science, 311, 804-805.

Lund C.M., Nicolau L., Gardner R.C., Kilmartin P.A., 2009. Effect of polyphenols on the perception of key aroma compounds from Sauvignon Blanc wine. Aust. J. Grape Wine R., 15, 18-26.

Obreque-Slier E., Peña-Neira A., López-Solís R., Zamora-Marín F., Ricardo-da-Silva J.M., Laureano O., 2010. Comparative study of the phenolics composition of seeds and skins from Carménère and Cabernet Sauvignon grape varieties (Vitis vinifera L.) during ripening. J. Agric. Food Chem., 58, 3591-3599.

Ollat N., Diakou-Verdin P., Carde J.P., Barrieu F., Gaudillère J.P., Moing A., 2002. Grape berry development: a review. J. Int. Sci. Vigne Vin, 36, 109-131.
Pagay V., Cheng L., 2010. Variability in berry ripening of Concord and Cabernet Franc in a cool climate. Am. J. Enol. Vitic., 60, 61-67.

Paul V., Pandey R., Srivastava G.C., 2012. The fading distinctions between classical patterns of ripening in climacteric and nonclimateric fruit and the ubiquity of ethylene - An overview. $J$. Food Sci. Technol., 49, 1-21.

Pilati S., Brazzale D.; Guella G., Milli A., Ruberti C., Biasioli F., Zottini M., Moser C., 2014. The onset of grapevine berry ripening is characterized by ROS accumulation and lipoxygenase-mediated membrane peroxidation in the skin. BMC Plant Biol., 14, 1-15.

Pinney, T., 1989. A history of wine in America: From the beginnings to prohibition. 572p. University of California Press, Berkeley.

Pisciotta A., Barbagallo M.G., Di Lorenzo R., Hunter, J.J., 2013. Anthocyanin variation in individual 'Shiraz' berries as affected by exposure and position on the rachis. Vitis, 52, 111-115.

Ribéreau-Gayon P.; Glories Y., Maujean A., Dubourdieu D., 2006. Handbook of Enology: The chemistry of wine. Stabilization and treatments. vol. 2, 2nd ed. 451p. John Wiley \& Sons, West Sussex.

Ristic R., Iland P.G., 2005. Relationships between seed and berry development of Vitis vinifera L. cv Shiraz: developmental changes in seed morphology and phenolic composition Aust. J. Grape Wine R., 11, 1-16.

Robinson A.L., Boss P., Solomon P.S., Trengove R.D., Heymann H., Ebeler S.E., 2014. Origin of grape and wine aroma. Part 1. Chemical components and viticultural impacts. Am. J. Enol. Vitic., 65, 1-24.

Robinson S.P., Davies C., 2000. Molecular biology of grape berry ripening. Aust. J. Grape Wine R., 6, 175-188.

Styger G., Prior B., Bauer F.F., 2011. Wine flavor and aroma. J. Ind. Microbiol. Biotechnol., 38, 1145-1159.

Sun Q., Gates M.J., Lavin E.H., Acree T.E., Sacks G.L., 2011. Comparison of odor-active compounds in grapes and wines from Vitis viníferas and non-foxy American grape species. J. Agric. Food Chem., 59, 10657-10664.

Tarter M.E., Keuter S.E., 2005. Effect of rachis position on size and maturity of Cabernet Sauvignon berries. Am. J. Enol. Vitic., 56, 86-89.

Teixeira A., Eiras-Dias J., Castellarin S.D., Gerós H., 2013. Berry phenolics of grapevine under challenging environments. Int. J. Mol. Sci., 14, 18711-18739.

Wang J., Luca V., 2005. The biosynthesis and regulation of biosynthesis of Concord grape fruit esters, including 'foxy' methylanthranilate. The Plant J., 44, 606-619.

Winkler A.J., Cook J.A., Kliewer W.M., Lider L.A., 1974. General viticulture. 2nd. Edition. 710p. University of California.

Zhu B., Wu Y., Xu X., Pan Q., Duan C., 2012. Changes of 3-alkyl2-methoxypyrazines in development Cabernet Sauvignon (Vitis vinifera) and Zuoshanyi (Vitis amurensis Rupr.) grapes from North China. S. Afr. J. Enol. Vitic., 33, 132-136. 